\title{
Adaptive Evaluation of Civil Judgment Recession in Iran and French Law
}

\author{
Hajar Moshayedi ${ }^{1}$, Vahid Khandany ${ }^{1} \&$ Ghavam Karimi $^{1}$ \\ ${ }^{1}$ Department of Law Science, Yasooj Branch, Islamic Azad University, Yasooj, Iran \\ Correspondence: Vahid Khandany, Department of Law Science, Yasooj Branch, Islamic Azad University, Yasooj, \\ Iran. E-mail: vahidkhandani1366@gmail.com
}

Received: March 21, 2016 Accepted: July 1, 2016 Online Published: July 31, 2016

doi:10.5539/jpl.v9n6p104 URL: http://dx.doi.org/10.5539/jpl.v9n6p104

\begin{abstract}
The main purpose of judgment is to protect the right and performing justice. The judgment is the tool to operate the justice and judge also the same as others is under the failure and fault. If any verdict is released in a judgment result that is accompanied with error, there is no doubt that it should be judged again juristically, therefore to have a vote free of error, the recession of judgment is predicted. Therefore in such condition that the law allows the voting court to be able to release adequate vote by considering the discovered realties about the struggle subject and ignoring previous vote and releasing the new verdict. In this article we try to evaluate and compare the judgment recession in Iran and French law weak and strength points so that if required it is regarded by the respected legislator of that country law.
\end{abstract}

Keywords: civil judgment regulation, judgment recession, verdict, establishment, judgment recession sides

\section{Judgment Recession Definition}

The judgment recession in the terminology that is combined of two terms; the judgment and recession. The recession is the root of reference and the infinitive Afal that means returning and to perform an activity again. To evaluate a claim juristically that is presented by the protester, it is called judgment by obeying legal regulation, therefore the judgment recession means the way of protesting about the regulations that includes the verdict which contains the validity about the terminated issue and it could be released from the issuing source which declared the failure due to the error in the voting and he could ask for re-voting due to the court mistake.

Reverse to the Iranian civil judgment regulation that has not presented any definition about the judgment recession, in new law the French civil judgment regulation has discussed about the judgment recession by defining in the article 593. This article considers that the judgment recession is the ignorance of the vote that has the validity about the judged issue and it is issued for new vote about the subject.

\section{The Judgment Recession Condition}

The judgment recession in civil judgment regulation of Islamic republic of Iran is one of the ways in protesting about the vote. Because this method is judged based on the court vote's certainty and the validity of judged issue, therefore in interpretation of related items there should be avoidance in extra interpretation and the operation territory is limited. One of the dependence condition to this method of complain is the approved verdict but here it is necessary that the judgment recession condition is evaluated in Iran and French civil law.

\subsection{The Judgment Recession Vote Condition}

The article 426 of civil law judgment regulation has defined that

About the rules which are finalized there might be request for judgment recession. According to the mentioned article the judgment recession is through complains that is released through the rules, therefore the court verdicts are not possible to be recessed. Other point is that not only verdicts which are issued definitely are possible to be judge, rather the reconsidering rules which are finalized due to reviewing request are also possible to be judged again at the defined time.

Therefore in addition to verdicts which are release definitely, the province reviewing court regulation, the courts verdicts which are released in financial disputes with financial struggles up to 3 million Rials and also regulations which are issued through basic courts by re-considerable method, the issued regulations in financial 
struggles by the demand of more than three million Rials and also the released verdicts of none fanatical cases and in definite duration are not reconsidered about their reviewing that could be the topic of judgment if one of the judgment recession id fulfilled.

The new regulation of French civil law in article 593 in definition that is presented about the judgment recession, has defined the judgment recession vote territory and believed that the judgment recession ignorance of votes have the validity about the judged issue and for issuing new vote about the verdict, the article 500 also has identified that the verdicts which do not have the reviewing capability have the validity about the judged issue, the same article in the second part also has defined that the reconsidering voted will find the validity about the judged issue when the pleading time for reconsidering is finished and in this duration no reviewing is demanded about the vote. Of course it is obvious that if the vote which is reviewable is reconsidered at the time of demanding, the reviewing court vote that is issued definitely has the validity of judgment, with in the articles 500 and 480 of French law we can conclude that the courts definite verdict in disputes actual agreements will have the same validity about the judged issue.

The complaint protests which have the combined effect about the issued vote are: reviewing, re considering and protesting about the subjects about the nationality, diverse and absence, therefore the re-protesting and claiming due to uncertainty will not have the validity of judged issue and they will not be possible to be judged again, therefore the voted which are possible to protested will have the suspending effect as in legal opportunity no any claim is done, it will be definite and it will have the validity about the judged issue and the protest will be done through the judgment recession, also the court vote in reviewing the votes in subjects which are possible to be protested will have the suspension effect through the judgment recession, if the judgment recession is discovered at the time of vote protesting and the protester could use through this way to remove the vote failure.

\subsection{Votes without Judgment Recession Possibility}

In the Iran civil law judgment regulation the judgment recession is not determined accurately and in some items if the vote is assumed not possible in recession, it will be the topic of criticize by lawyer, here we discussed about the votes which are not possible to be recessed and samples in which there are doubts.

\subsubsection{Agreement}

The article 426 of civil judgment regulation declares that the regulations might be definite, the judgment recession there might be some demands, according to the mentioned article it is obvious that the Iran legislation only assume the rules possible for judgment and the judgment recession for agreements even the disputes definite agreement and the provisional agreement in the including concepts as the protester providing agreement and the temporal order is predicted, there might be proclamation that the legislator in application of term ( rule) in article 426 and other items does not have the permission in the agreement in special order, rather his idea is attended to the vote including the verdict and agreement in contract to the term judgment in French language.

Therefore the agreements are also possible to be judged in recession that it seems that such proclamation is not acceptable because in new regulation the civil judgment regulation the writers have tried that the terms, verdicts, regulation and agreement in it an accurate meaning of legislation is applied and the rule makers in some previous articles related to the judgment recession in protesting discussion the article 366 and next and protest of third party (article 417 ) and next which are two other methods in exclusive method of complain about the court decisions, has been clarified obviously and repeatedly about the rules and agreement, it is removal that in judgment recession discussions, the agreements are forgotten or the term (rule) in the meaning as the agreement is applied and if most of writers have written about the civil law regulation, they would have doubts about the agreements judgment recession possibility.

The French legislator in article 593 of civil judgment regulation at the position of judgment recession possibility vote has used the term judgment that means the vote. It is natural that some of the agreements are not possible to be judged due to lack of validity in terminated issue.

\subsubsection{The Judge Vote}

The judge vote in civil judgment regulation is not possible to be judged because the article 426 on this rule is supervising the court rules and not the rules which are issued based on the article 454 and after the civil judgment regulation, considering the court about the judge vote is limited to the mentioned items in article 489 and it is on a way that the predicted sides in judgment recession after the judge verdict issuing is also possible. In the regulations about the internal judgment $/ 9$ items 45,501 of civil judgment regulations) no nay duty is predicted for this issue, according to article 490 of civil judgment regulation the judge verdict in mentioned 
items at article 489 within 486 days after the announcement is possible to be protested at the court where the dispute is referred or the court that has reviewing competency and it seems that the rule that the court is releasing to evaluate the protest includes the article 426 of civil judgment regulation and it is possible for judgment recession, in French law the judgment recession compared to the judge votes and the same conditions that is determined for the courts votes s predicted in the article number 1491 od judgment regulation of this country and mentioned article is the source of judgment recession demand for the judge verdict in research courts which has determined the competency to review the complains about the judgment votes. According to what has been mentioned before it seems that it is better that in civil judgment regulation some corrections are fulfilled and the judgment recession about the judge vote is accepted so that the mentioned defect is removed in internal judgment.

\subsubsection{Country Supreme Court Verdict}

The country supreme court is the source of evaluation of protests about the basic courts votes and reviewing, the articles 367, 368, 369 of Islamic republic of Iran includes of adaptation realization or maladaptation of votes about the protest demanding equal to the legal regulations and principals

In the French law the lawyers believe that by documentation according to the article 593 of civil law the country supreme court does not have the capability to the judgment recession because in this article the purpose of judgment recession has been determined as the reconsideration of dispute in the subject of issue in the verdict and it is on a way that evaluation in the country supreme court is the formation of this issue and this source is not involved in the dispute identity as the position of judgment.

In Iranian law attention to the country supreme court has been mentioned in article 366 and only the evaluation should be done according to the French lawyers deductions because the purpose of judgment recession is considering the dispute again in the subject and in the verdict, therefore accepting the judgment reslcession about the votes of this source is not defendable, the judgment process also approve this idea.

\subsubsection{The Semi Jurisdictional Source Votes}

The votes of semi jurisdictional sources as the financial disputes committees and struggle soling tams in the working law and the supervision teams in the documents and properties registration law is not possible to be judged because in these regulations there in no pointing out to the method of complain about the rules and it is on a way that all necessities which predicts the judgment recession about the courts verdicts also exist in the source generally

In the French law, the judgment recession in the law first book has been predicted items 603-593, according to the article 749 of the same rule, the first book regulation within the judgment systems in civil, commercial, social, agricultural and laboring issues is considered by the operator, except in items that special items are predicted about the matters specific for judgment source.

As the result the judgment recession in French law is possible toward all votes of judgment source

\subsubsection{The Correcting Report (Judgment Contract)}

The dispute parties might solve the disagreement between the parties and they can freely determine the conditions, every time the agreement is fulfilled in the court, the agreement subject and its condition that is occurred in the meeting is signed by the judge and both parties, article 182 of civil judgment regulation. This agreement is name as the corrected report or the judgment contract due to the adjustment by the judge and because of its format which is similar to the vote.

In French law, the jurisdictional contract is not possible in judgment recession

In Iranian law we can deduct the same, first the contract is not considered the judgment vote and relatively it does not have the issue validity and secondly this contract is possible to be invalidated in the adjusting court, the compromising parties should respect the contract items to be able to ask the court it accept its cancellation due to disagreement with public order or mistake and also it has the right to terminate because of failure and problems or similar issues unless the conditions provide the party to be free in his desire and finish the struggle determinately.

\section{The Judgment Recession Demand Sides}

The judgment recession damages the rule solidarity and weakens the rules validity; therefore using them is really limited and rules are only applicable in conditions that are determined by the law. In the ljudgment minute also the side is considered that mentioned in the judgment recession demand consideration 
The article 426 of the judgment regulation is exclusively dependent to the actual rule and secondly the aspects are defined in seven articles, in the French law the judgment recession aspects are declared in article 595 of judgment regulation that are limited and based on the reality discovery that is covered during evaluation to the court and it leads to the incorrect decision. By comparing the judgment recession aspects in Iran and French we realize that some of the directions are common in both but in reverse the considerable number are leads to judgment recession in Iranian law.

\subsection{Common Sides}

The trick and cheating, discovery of documents is the basis of the verdict and document discovery in Iranian law and also in French are possible in judgment recession

\subsubsection{Trick and Cheating}

According to the clause 5 of article 426, the civil judgment regulation, the trick and cheating in the other party is effective in the judgment recession and court verdict, based on this item it is necessary that the used trick that means the cheating proceeding is by intention of tricking the court and second the trick and cheating is used by any person that is the dispute party and the verdict is issued in his favor.

Other point is the necessity of affecting the trick in the court verdict. The effectiveness of trick in court means that issuing such verdict is the result of cheating, as if there was no cheating, no rule is released for, it is necessary that the cheating and trick is revealed after the rule issuing because if the trick is revealed before the rule issuing, the effect of problem on the rule is nullified.

In cheating clause 1 of article 595 in French civil judgment regulation it has been mentioned that due to this article one of the judgment recession aspect is that after the vote issuing it is identified that the court decision has been under the effect of any person cheating that the vote is issued in his favor, by comparing this article and the clause 5 of article 426 of Iran civil judgment regulation it is identified that conditions are the same in both articles about the cheating.

\subsubsection{The Document Fake Prove}

In country law the faked prove of document that is issued by the court has been mentioned in the clause 6 of article 426 of judgment regulation from the judgment recession aspects, based on this clause it is necessary that the document is the approval of the verdict that means the court verdict is document accordingly, it is necessary that the document fabrication is approved by the final vote and since the document fabrication prove, during the determined opportunity, the judgment recession is demandable. To realize the faked document, $f$ any defect is realized in the judgment recession, it is effective in the court judgment, on a way that if such document is not existed or its fabrication is proved before the verdict issuing, such verdict is not issued.

In French law at the clause 3 of article 595 the civil judgment law is based on the court consideration on the documents whose fabrication s realized after the vote issuing or $t$ is announced through the jurisdictional process, through the judgment recession it has been declared that in this article in addition to document faked issues after the judgment recession demand with reviewing the proved judgment rule, items which are proved faked to the court are declared according to documents.

The conditions of this clause s similar to the clause 6 of article 426 in our country civil judgment rule and the difference is that in contrast to our country law in which the document fabrication should be proved by the final rule and the judgment recession duration is the tile of this verdict and in the French law this direction is not limited to the judgment verdict and items which are proved without the previous jurisdiction announcement, the document fabrication in the evaluating court is approved by reasonings and due to article 596 of judgment regulation law the judgment recession interval is two months from the announcement after the document fabrication prove.

\subsubsection{The Hidden Documents Accessibility}

The clause 7 of the article 426 of judgment regulation about accessibly to the rule issuing about the documents that is the reason of pleader for judgment recession and it is hidden in the judgment recession and it is not the applicant intention and it is not informed in the judgment recession even in items in which the other party does not have role in rejection of rule, of course it is clear and logical that the rejection should not be from the applicant. In the French law in clause 2 of article 595 of civil judgment regulation accessibility after the vote issuing is determination of documents that is announced by the opposite party of neglecting that has been declared through the judgment recession, that means In contrast to the Iranian law it is not necessary to hide the document by the opposite party, in the French law the document is neglected from the judgment recession 
requirements, if it has been done by opposite party.

\subsection{Exclusive Sides}

Reverse to the common sides between the Iranian and French law there are some sides that only in one of these two countries leads to the judgment recession that we here discuss about them

\subsubsection{Exclusive Sides in Iranian Law}

In Iranian law due to articles 1 to 4 of civil judgment regulation, the rule issuing in other items of pleader claims or more than the demands and controversy presence in the verdict contents and issuing the controversial rule issuing with the verdict that is released about the same dispute and its owner are introduced for about the judgment recession, but these directions are not realized in the French new judgment regulation, regardless of some items, under other titles are considered, according to the realized verdict and due to articles 617 and 618 of the same law, the controversial votes issuing are introduced on the vote defect aspects in the country court, the upheaval which is not fulfilled in the French law about the judgment recession and in the French law it has reduced the judgment recession and this issue is due to the judgment recession condition as one of the exclusive methods of complain that is based on the judgment errors correction that occurred due to incorrect proceedings of dispute and on the other hand items as verdict issuing except the dispute subject or before it includes great mistakes and in the verdict it is named as the written errors and the cause of verdict correction.

\subsubsection{French Law Exclusive Directions}

Due to the clause of article 595, the judgment regulation of French, the judgment basis on the witness is on the promise and vow given after the vote issuing and its controversy with reality is announced, in our law it is not declared clearly regardless of lying vow assumption as the example if trick and cheating. It seems that the trick and cheating in Iranian law in cases where the dispute parties forced to tell lie, is true but cheating in lying is in doubt because in Iran the vow is the topic of dispute.

\section{The Judgment Recession Moratorium and Its Beginning}

In Iranian law according to the article 427 of civil judgment regulation the moratorium for pleader of Iran citizen is 20 days and for people outside of country is 2 months and mentioned moratorium is started about the rejected documents since the document reception date and if the document is faked the start of judgment recession is since the final verdict announcement, also if the judgment recession is against two verdicts the moratorium will be based on the last date of both verdicts announcement.

In French law, the judgment recession moratorium has been determined 2 months in article 596. The operational guaranty of the disobedience has been determined as none-auditable dispute. To start the moratorium two conditions are necessary, first the pleader should have the understanding about the judgment and also the verdict should be declared to him, the clause 2 of the article 596 of French civil regulation says that (the time of judgment recession is started from the date that the dispute party find understanding about the judgment recession, that means the dispute party cheating is revealed or documents of other party s obtained or the court vote is based on the document fabrication or the court vote is based on the vow lying or promise of other party that is the base of court verdict, the court vote $\mathrm{s}$ definite about this item.

\section{Disputing Parties in Judgment Recession}

In Iranian law, the pleader and pleaded the first judgment and the agents of both parties have the right to ask for judgment, heritage only can ask for judgment when the dispute subject party is not dead, for example if a person is sentenced to a document and he is dead, his heritage could ask for judgment recession if the document fabrication is proved in the defined moratorium. The death of sentenced party if other conditions are provided could not avoid the judgment recession against his heritage, regardless of article 130 of civil judgment recession that allowed the third party entrance, due to article 441 of the same law in judgment recession except the dispute parties other parties could not inter to the dispute at all and therefore the third party is also banned to enter to the judgment recession. In the new regulation the civil judgment regulation of French had been determined in the articles 594 and 534 that what people could ask for judgment recession, according to the article 594 the judgment recession could not be asked unless the dispute or their legal agents demand it, the article 441 of the same law also has identified that in judgment recession except the dispute parties other person cannot enter to the dispute.

Generally determination of dispute parties are not faced with serious problem because dispute parties are the pleader and pleaded or reconsidering party, also those parties as the third side lead to issuing a verdict for the judgment also regarded the dispute party, the reason according to which the third party is banned in judgment is to keep third party right, therefore the third person who suffer from the vote could ask for reconsideration vote. 
Different type of judgment recession:

In Iran there are two type of judgment regulation according to the article 432 of judgment regulation:

A- the judgment recession that is pleaded directly and the judgment requires the pleading presentation, according to the article 435 of the same rule in pleas for judgment recession, the name, family and living place of pleader and his party ids written and also the vote specifications and the side which is the recession part is also written.

B- The judgment recession which is according to the article 432 of judgment and presented as the reason and the person for whom the vote is documented should prove its invalidation for ineffectiveness.

To fulfill the judgment recession, there should be a dispute in the court and in the legal judgment it is presented as the reason and the vote also should be effective in dispute and also there should be a recession aspects and pleads is presented in moratorium and in contrast to the judgment recession there might be a court that evaluates the dispute and it is not the same with the court that accept the pleading.

In the judgment regulation of French civil judgment it is not defined obviously but the article 598 and 599 of this article is understood that in that legal system naturally there is the judgment recession. Clause 1 of the article 598 identifies that the judgment recession is formed briefly, therefore in the judgment recession pleading o p-resent different sides, the depending is done, therefore in judgment recession request, the common request explanations is nullified. The trial recession is considered as the justice methods and it is evaluated as the method of considering the main dispute by the court where the complain is made, therefore in contrast to the Iranian law according to which it is necessary to present pleasing for judgment, there is no such condition in French law.

According to the article 599, if one of the parties declares that he has intention to ask for judgment for the vote, the court could post pond voting, therefore because the judgment recession is considered as the complain recession method it is necessary that to pleads verdict is announced.

The regulation for considering the judgment recession in Iranian law after the plead presentation to the court, the issuing court release the required vote in acceptance or reject of judgment recession and if agreed it proceed to evaluate the identity, therefore the judgment recession pleading is done in two sections, first evaluation of judgment recession pleading and if accepted the evaluation of rest, therefore the court should release the acceptance or reject of pleading. The court should identifies that the request for accepted moratorium is led to release of judgment recession and requested vote is considered as the judgment votes which are possible for recession and if the acceptance order is issued, the order is announced as the verdict o parties, due to article 436 in judgment court, only the written recession pleading is considered. On the other hand other party could present proper failure about the attached documents and presentation of third party is banned in the mutual dispute.

In French law, the judgment recession is considered through the trials and like the evaluation of main disputes by the court in which the pleading is made, the case will be reviewed but in contrast to Iran where the judge could not accept the dispute judgment recession, during a vote compared to the pleading acceptance and dispute identity, the vote is released, article 601 of French law has identified that if the judge accepted the pleads for judgment recession, he will give the same vote for the dispute identity unless there is need for complementary research, therefore the judge could take a decision during a vote about the plead acceptance and identity at the same time. Conditionally due to evaluation of dispute identity does not require other researches.

\section{Judgment Recession Pleading Acceptance Effects}

\subsection{Suspension Effect}

Because the judgment recession is approved through the complain, the judgment recession and even judgment recession about the vote will not stop its operation and due to the clause A of article 437 if the punishment is not financial, the judgment recession will stop the verdict operation and according to the part B of mentioned article is he is not sentenced financially and there impossibility to take and compensate damages in the court decision the vote for committed party is taken properly and operating the vote is continued and mentioned operation is remained blocked to the final result and court will order to continue the operational procedure when there is the possibility to tale possible damages and the possible damages means the operational procedure obstacles which is burdened to the committed party and if the vote is nullified it should be compensated from the committed party and the type of provision is identified from the legislator and it could be the cash, guaranty or unreal propertied. It is understood from the mentioned article that by releasing the judgment recession acceptance, the rule is to stop operational procedure.

Unless he is punished financially and the committed person has the proper provision to continue the verdict 
operation, the operational procedure is stopped when the vote is under operation and if it is operated the judge should not decide about the operation condition until the judgment recession vote issuing, according to the public regulations because the court cannot solve the dispute unless the person or beneficial people ask for the dispute solving, in this case the judge should not proceed rather by plead of judgment applicant who will not follow special ceremonies, the judge will issue the final result for judgment unless he is sentence financially and the committed asks for its continuity in this case by taking operational provision the procedure is continued of course it is obvious that the rules which have the informing will not follow this article.

The article 579 of French law has identified that complains exclusive methods and the moratorium which is determined for its demand does not have suspension effect on the rule operation unless the law is identified against it. No other article will allow the judge to stop the judgment, therefore it is observed that in the civil judgment of French the principal is to operate the rule definitely and up to the extent that it impossible, the rules operation obstacles should be removed and even the judgment recession acceptance does not stop its operation.

\subsection{The Transference Effect}

The judgment recession in the extent has the transferring effect that means the court in the case of vote nullification should take decision about the subject issue

The article 593 of French law that is on the judgment recession definition statue has described the judgment recession transferring effect, that judgment recession is the method of complain in order to reject the vote which has the validity for the terminated issue so until time the judge will take the decision about the subject, therefore issuing the expert agreement, research and location evaluation and etc. is possible for the recession and it is the necessity to have the transference effect that all dispute parties are invited for the judgment recession voting. The article 597 of French law has put the parties' invitations duty on the pleader and even it has assumed the operational guaranty as the impossibility to the judgment recession pleading application. In Iran law such duty is not determined for the judgment recession pleaders but it seems that the general regulation will obviate the conditio9n because in reality the judgment recession might change the rights of judgment recession pleader vote rights

\section{Conclusion}

As the result about the votes of judgment recession in the Iranian civil law we can say that first of all about the identity of voting which his possible for judgment recession, no any reason exists about the actual verdicts and there is no any dispute actual agreements in votes inclusion, therefore the article 426 correction is necessary and it is suggested that instead of the phrase; the finalized verdicts, the tern the finalized votes are used so that the dispute actual agreements are also be possible to presented in judgment recession, secondly from the issuing source side, the vote foe civil judgment regulation correction as including all none committing issues in all none retribution sources will be really proper and even essential and it should be explained that in the French law the judgment recession in the first volume of French law has been predicted in articles 63 to 593 and according to the article 749 of the same rule, the first book regulations in all judgment sources that are operational in the civil, commercial, social, agricultural and laboring and client issues. Except in some cases that the special regulations is predicted about the judgment sources and it seems that the French legislation innovation in reduction of judgment recession aspects reduction and elimination of some items which had been introduced previously and attention and effectiveness of them under the title of rules correction to protesting is the logical and interesting innovation and in civil judgment regulation of our country could be paid attention.

\section{References}

Ansary, Masud, Taherrie, Mohammad Ali. (1384). private laws magazine (1st ed., Vol. 1). Tehran. Mentality publication.

Couchez, G. (1998). Langlade, pierre et lebeau daniel, procedure civile Dalloz. Paris.

D'ambra, D. (1995). in, encyc, Dalloz, rep, pr. Civ.

Hassan Zadeh, M. (1390, Winter). adaptive study of judgment recession in Iran law and French, adaptive law researches, $15^{\text {th }}$ edition.

Hayati, A. (1387). judgment recession (1st ed.). Tehran, mizan publication.

Heron. J. Droit judiciaire prive. Paris, 1991.

Katuzian, N. (1376). the validity of judged issue in civil disputes (5th ed.). Tehran, judgment publication.

Matin Daftarie, A. (1343). civil judgment regulation and commercial train rules (2nd ed., Vol. 2). Tehran. 
Vincan, jean et Guin chaed, serge, procedure civil, Dalloze, paris, 23e e. 1994.

\section{Copyrights}

Copyright for this article is retained by the author(s), with first publication rights granted to the journal.

This is an open-access article distributed under the terms and conditions of the Creative Commons Attribution license (http://creativecommons.org/licenses/by/4.0/). 